\title{
Risk management and quality of care
}

\author{
Fiona Moss
}

\begin{abstract}
An honest concern about quality, however genuine, is not the same as methodical assessment based on reliable evidence. ${ }^{1}$
\end{abstract}

Risk management is about reducing the likelihood of errors. Its particular aims are to reduce errors that are costly in terms of damage, discomfort, disability, or distress to an individual and to limit financial loss to an organisation. Risk management achieves this through detecting, reporting, and correcting actual or potential deficiencies in the process of care that, however small, could lead to a significant and costly mistake. Risk management programmes therefore involve all aspects of work, production, and interactions within an organisation - and in health care this includes looking beyond clinical care. An established and well run risk management programme contributes towards providing hospital care that is free of mistakes and it makes a clear contribution to healthcare quality. The benefits to patients of care in a hospital whose treatment can be guaranteed to be as safe as possible are obvious. But risk management is only one of a clutch of programmes whose aim is to improve quality of care, and reducing harm is only one aspect of healthcare quality. Linking risk management programmes with other quality initiatives will help to develop a coherent approach to quality improvement within a hospital or practice.

This paper will explore some of the ideas and definitions of quality of care and examine the particular contribution of risk management with some other quality initiatives to improving different aspects of healthcare quality.

\section{Quality of care: what does it include?}

Healthcare quality is much more than a matter of technical or professional performance, but it is difficult to sum up the individual components of good quality care. Much care is to some extent a series of compromises, trade offs, and choices, made, in the best circumstances, by properly informed patients guided by knowledgeable healthcare professionals in safe and comfortable surroundings. Good quality care incorporates appropriate and competent technical care with opportunities for patients to make choices and to discuss concerns and fears, and it should result in an outcome appropriate to the problem. Even this long and cumbersome description excludes some important aspects of good quality care, such as fairness and access, and assumes much in the phrase "competent technical care" and says little about the organisation of care.
CLASSIFYING QUALITY OF CARE

Three classifications provide a useful framework for discussing quality of health care. The first, the basis of much work on quality improvement, is Donabedian's classification of health care into its structure, process, and outcome components as targets for quality assessment. ${ }^{2}$ The second is the six dimensions of quality described by Maxwell as part of a discussion on the need for an integrated quality improvement programme based on methodical assessment (box). ${ }^{1}$ The third, also from the
Dimensions of quality
- Effectiveness
- Efficiency
- Appropriateness
- Acceptability
- Access
- Equity

work of Donabedian, considers health care in three parts: the technical aspects of care, the interpersonal aspects of care, and the amenities or the environment in which health care is provided. $^{3}$ Of course, these classifications overlap, but each approaches the definition of quality of care differently and together they provide a more complete picture than each alone. By combining structure, process, and outcome with the six dimensions of quality a structure emerges that can be used to compile a series of questions about the quality of, say, an intensive care unit (box). ${ }^{4}$

\section{Structure, process, and outcome}

The structure of care describes the resources that combine to deliver care and includes all aspects of the environment of the hospital, clinic, or practice premises where patients are seen and treated. Structure includes the number and grades of staff as well as the number of beds, the number and configuration of clinics, and the availability and standard of equipment and other items necessary for delivering health care. Clearly, some aspects of structure, although desirable, are not crucial for good quality care and, conversely, bad care is quite possible within a well equipped hospital.

The process of care refers to all the events, procedures, and actions included in the health care received. This includes assessments such as clinical examinations and investigations, clinical interventions such as prescription of a drug or an operation as well as outpatient appointments, and the processes of nursing care and therapy. The interpersonal aspects of care may also be considered part of the process of care. 


\begin{tabular}{|c|c|c|c|}
\hline \multicolumn{4}{|c|}{ Assessing quality in an intensive care unit } \\
\hline & Structure & Process & Outcome \\
\hline Effectiveness & $\begin{array}{l}\text { Staffing level and skills } \\
\text { Equipment } \\
\text { Access to theatres, etc }\end{array}$ & $\begin{array}{l}\text { Workload (volume of } \\
\text { patients treated) } \\
\text { Compliance with protocols, } \\
\text { where relevant } \\
\text { Data based peer review } \\
\text { Infection and } \\
\text { complications rates }\end{array}$ & $\begin{array}{l}\text { Survival rates compared } \\
\text { with similar units for } \\
\text { matched cases }\end{array}$ \\
\hline Acceptability & $\begin{array}{l}\text { Is setting frightening or } \\
\text { reassuring? } \\
\text { What provision is there for } \\
\text { relatives (privacy for } \\
\text { counselling, overnight } \\
\text { accommodation)? }\end{array}$ & $\begin{array}{l}\text { Is explanation to relatives } \\
\text { required and recorded in } \\
\text { notes? }\end{array}$ & $\begin{array}{l}\text { Is there follow up of } \\
\text { patients and of relatives to } \\
\text { obtain their opinions and } \\
\text { suggestions for } \\
\text { improvement? }\end{array}$ \\
\hline Efficiency & $\begin{array}{l}\text { Avoidance of extravagance } \\
\text { in structure, equipment, } \\
\text { and staffing }\end{array}$ & $\begin{array}{l}\text { Throughput, staffing, etc } \\
\text { Admission and discharge } \\
\text { arrangements }\end{array}$ & Costs for comparable cases \\
\hline Access & & $\begin{array}{l}\text { How many patients } \\
\text { suitable for admission have } \\
\text { to be refused because the } \\
\text { unit is full? }\end{array}$ & $\begin{array}{l}\text { What actually happens to } \\
\text { patients refused or delayed } \\
\text { admission because the unit is } \\
\text { full? }\end{array}$ \\
\hline Equity & & $\begin{array}{l}\text { Is there any evidence of } \\
\text { bias in who is admitted or } \\
\text { how they are treated? }\end{array}$ & $\begin{array}{l}\text { Is there any evidence of bias } \\
\text { in outcomes? }\end{array}$ \\
\hline Relevance & $\begin{array}{l}\text { Bearing in mind other } \\
\text { needs, is this service an } \\
\text { appropriate use of } \\
\text { recources at the current } \\
\text { activity and expenditure } \\
\text { level? }\end{array}$ & & $\begin{array}{l}\text { How much difference does } \\
\text { the unit make to survival } \\
\text { and health status, and for } \\
\text { whom? }\end{array}$ \\
\hline From Maxwe & & & \\
\hline
\end{tabular}

The outcome of health care is any change in a patient's health status attributable to a healthcare intervention and includes restoration of function, relief of symptoms, and improvement in life expectancy. Improving health - either current or future - is a central aim of health care. Knowing what works or what is effective is important to individual patients and to healthcare providers, purchasers, and policy makers. Measurement of outcomes is of crucial importance to assessing health care and attempts to improve effectiveness and efficiency. Outcomes might seem to be a measure of the sum of all that goes into health care - an outcome less than expected might indicate poor quality care. However, measuring outcome is not always straightforward; a change in health status of an individual must be directly attributable to a healthcare intervention to be classed as an outcome of health care - that is, a direct causal link must exist between the result and the intervention. ${ }^{5}$

Assessing outcomes of clinical interventions has mostly been described by healthcare professionals and expressed largely in terms of physiological or other technical measures. Thus the outcome of the use of inhaled steroids in patients with troublesome nocturnal asthma is understood technically in terms of change in the morning peak expiratory flow rate. But what matters for the patient may not be so much this criterion but a reduction in symptoms and undisturbed sleep.

Measuring the outcome of a clinical intervention implies assessment of a change in health status. Some measures of health status are condition specific - for example, changes in blood glucose concentration in diabetes. Generic measures express changes in health status that apply to any condition and describe three domains of wellbeing: physical functioning, mental health, and social function. The development and validation of health status questionnaires such as the SF 36 questionnaire ${ }^{6}$ offer a means of comparing outcomes across specialties. The use of health status measures permits an understanding of the impact of clinical interventions on patients' wellbeing and, when used alongside conventional clinical and physiological measures, adds to the information on effectiveness of interventions.

\section{DIMENSIONS OF QUALITY}

Effectiveness is the extent to which a healthcare intervention, when used in routine practice, achieves the desired outcome. ${ }^{7}$ From all perspectives - those of patients, providers, and purchasers - promoting the use of effective interventions and limiting the use of ineffective ones is an important focus for quality improvement programmes. However, evidence exists that some patients are treated with ineffective interventions and others who would benefit from specific effective treatments do not receive them. One example of the use of ineffective care is the continued use of dilatation and curettage for women under 40 with menstrual problems, for whom this procedure is unlikely to have any benefit. Among patients not always receiving effective interventions are those admitted with acute 
myocardial infarction, some of whom do not receive $\beta$ blockers and aspirin, which prevent further infarction. ${ }^{8}$

Appropriate care has been defined as ". . . the selection, from the body of interventions that have been shown to be efficacious for a disorder, of the intervention that is most likely to produce the outcomes desired by the individual patient." Again, there is evidence that interventions are at times used inappropriately. One example is the use of coronary artery surgery in coronary artery disease; in one health region in the United Kingdom $16 \%$ of coronary artery bypass surgery, assessed retrospectively by a panel of experts, was found to be inappropriate. ${ }^{11}$

Good quality care must be acceptable. The working group who defined the appropriateness of care quoted above emphasised the importance of the individuality of the patient, the social and cultural context, and the availability of healthcare resources when considering appropriateness of health care. Appropriate care goes further than just medico-technical concerns and must include a measure of acceptability to the patient and to society (box). Thus the assessment of the appropriateness of coronary artery surgery referred to above may have underestimated its level of inappropriate use as the study examined appropriateness from only a medicotechnical perspective and did not investigate patient choice or other criteria.

Assessing the acceptability of care is difficult. No mechanism exists for routine collection of information about the acceptability of interventions to individual patients. The weight an individual places on risks of treatment and likelihood of a treatment working is not always predictable. And societal attitudes to acceptability of care are not always explicit. A recent case reported widely in the British press of a 10 year old girl who had experienced a relapse of leukaemia after a bone marrow transplant illustrates the tensions that may emerge when differences exist between the acceptability of an intervention as perceived by an individual (represented by the girl's father and his legal advisers) and by society (represented by the purchasers of care). The

\section{Additional criteria for appropriateness of an intervention $\star$}

Availability of technical skills and resources to allow intervention to be performed to a high standard

Intervention performed in a manner acceptable to the patient

Patient to have adequate information about the range of effective interventions

Patient to be fully informed of and to be involved in discussions about likelihood of adverse outcomes

Patient's preferences to guide choice of intervention

Patient's preferences should reflect both primary outcome and perceptions of potential adverse outcomes

^From working group report" purchasing authority, having taken medical advice, refused payment for further transplantation, estimated at $£ 75000$, as there was judged to be only a minimal chance that treatment would be successful. Its view was that the girl should be made as comfortable as possible and not given active treatment. But the girl wanted to pursue active treatment. The case went to the Appeal Court, which ruled in the purchasing authority's favour. ${ }^{11} 12$

Acceptability of care to an individual may be as much about the interpersonal aspects of care as the technical task of delivering care. Healthcare professionals need to be good at communicating if patients are to be able to make choices and to decide what is to them acceptable. Allowing people to make choices requires respect and sensitivity.

Access to care, in terms of waiting lists, is perhaps the most easily measured of all the dimensions of quality and in the United Kingdom has become a matter of political concern. Debated in the media, access to care as defined by waiting lists for operations and for first outpatient appointments has a greater profile than other aspects of quality of care. The patients' charter has set out standards that may help improve the way that hospitals manage waiting for appointments within hospital clinics. ${ }^{13}$ The easy availability of data on waiting lists may give undue weight to one aspect of quality at the expense of others. This is illustrated by a case of a child who had been waiting for 12 months to have an ear operation and that became public in the run up to the general election in 1992 in the United Kingdom. The political furore and media discussion that followed focused on access to care and paid little attention to consideration of more pertinent issues, such as the appropriateness of the procedure. ${ }^{14}$

Equity is about fairness and assuring that healthcare delivery is related to need and is a specific aspect of access to care. In the United Kingdom the health care provided by the National Health Service is based on equitable principles and is free at the point of delivery. Access to care is related to need and not, for example, to ability to pay. This contrasts with much health care in the United States. But equity has a wider application than just the system of health care and within the health service in the United Kingdom examples of inequity can be found. People whose first language is not English may have a restricted access to advice and care, unrelated to need, if they are unable to explain their problems fluently to the doctor because of lack of interpreting services. The introduction of fundholding for some general practices has led to concern that the patients of fundholding general practitioners may get preferential access to some aspects of hospital care as their doctors control budgets for elective care. And studies in both the United Kingdom and United States have shown that women with coronary artery disease are less likely than men with similar disease to have coronary angiography or surgery. 
INTERPERSONAL AND TECHNICAL ASPECTS OF CARE

The third classification of the quality of care includes a distinction between interpersonal and technical aspects of care. Practitioners require skills in both in order to deliver good quality care. Being able to discuss the risks and benefits of interventions and describe possible outcomes is a prerequisite if patients are to make informed choices. Technical competence is crucial but alone will not guarantee good quality care.

\section{Systematic approaches to quality}

The range of questions encompassed in the notion of the quality of care - from details of the effectiveness of technical interventions to equity and respect - indicate the enormity of the task of its assessment. Risk management deals with only some of the dimensions of quality and targets adverse events and aims at reducing errors. A quality improvement programme that relied only on risk management might reduce risk and result in a safer hospital but would not, for example, tackle issues such as effectiveness or appropriateness of care. Each quality programme has a particular perspective and a contribution to different aspects of the quality of care.

A jungle of terminology and the differing functions and origins of programmes that focus on the quality of care have made this seem a perplexing area to many healthcare professionals. I shall describe quality programmes briefly in three broad categories: quality assurance, quality improvement, and clinical audit. Although each may have a different emphasis they all entail a systematic approach to assessing quality of care.

\section{QUALITY ASSURANCE}

Quality assurance, which has had greater prominence in the United States than the United Kingdom, tends to rely on measurement of indicators of performance. Broadly, quality assurance systems rely on external inspection. One aim is to guarantee that an organisation meets predefined standards and may be described as a checking mechanism. In the United States since the 1950 s external monitoring agencies have accredited hospitals and monitored the quality of care. The system is complex and is a mix of private and public organisations whose objectives include cost containment as well as quality improvement. ${ }^{15} 16$

External quality assessment and accreditation have not been a major feature of health care in the United Kingdom. But examples of mechanisms for external checks on quality do exist and include the quality assurance system for chemical pathology; the Health Advisory Service, set up to inspect services for long stay elderly and mentally ill patients; the confidential enquiry into maternal mortality; and the confidential enquiry into perioperative deaths conducted by the Royal Colleges of Anaesthetists and Surgeons. ${ }^{17}$

The confidential enquiry into perioperative deaths (CEPOD) has had an important im- pact on the organisation of emergency surgery particularly on procedures performed out of hours. By focusing on possibly avoidable serious events this enquiry is similar to the process of risk management. Furthermore, it is based on a reporting system another important element of risk management. Local risk management programmes should work closely with those involved in CEPOD.

\section{CLINICAL AUDIT}

The introduction of medical and then clinical audit into the United Kingdom health service in $1990^{18} 19$ represented a fundamental change in approach to the quality of clinical care. Until then the approach in hospitals was rarely systematic. Discussion about methodical approaches to quality assessment was limited to groups of enthusiasts. But backed up with specific central funding of $£ 48 \mathrm{~m}$ annually medical audit very quickly became part of the contractual commitment for hospital doctors and a near mandatory activity for general practitioners. In the definition of audit included in the Department of Health's documents medical audit was described as a professional activity. At first, audit was apparently only for doctors. But this inward approach changed and medical audit was superseded by clinical audit, which has a wider remit by including the work of all healthcare professionals.

The principles of clinical audit are described in the notion of the audit cycle. ${ }^{20}$ Using the best evidence available - from scientific publications or nationally agreed standards or locally agreed codes of practice - local practice is measured and compared with the agreed standards. Appropriate sampling methods and sample size are necessary to ensure that the data give an accurate view of the aspect of care being examined. After discussion of the results with the relevant healthcare professionals any difference between the agreed observed standards is analysed and attempts are made to find the reason for any difference so that changes can be made with a view to improve practice. $^{21}$ Thus a quantitative approach is used to gain a picture of the standard of care. But the action needed to change practice is often less clear, which may explain why audits often fail to change practice and improve quality.

The success of this service wide implementation of clinical audit in improving patient care has not been formally evaluated, and the benefit of this investment is not known. ${ }^{22}$ Nevertheless, clinical audit is now established in the United Kingdom as the focus of quality assessment in hospital practice. Most hospitals have audit meetings, designated audit officers or facilitators, and a programme of topics for audit. Direct central funding for audit has now been passed to the purchasing authorities. Audit continues as a provider function, but purchasers can now add some external pressure by including quality statements in contracts and asking for audits of specific topics. 
QUALITY IMPROVEMENT

The essential features of quality improvement are that it is largely an internal mechanism; that it is reflective and not punitive or defensive; that it relies on learning and improving; and that it is based on an understanding of the needs of the customer and on good evidence. Compared with quality assurance, quality improvement does not primarily set out to determine whether care is substandard or not or whether it meets a set standard, but it is a more dynamic approach to quality that relies on systematic analyses of the processes of work - quantitative or qualitative - that are considered and used by those doing the work to improve what they do. All healthcare professionals and all who work in health care should be involved; quality improvement is not a specialty or discipline in its own right. To bring about change those involved in quality improvement must not only undertake methodical study but also understand how their organisation works and what motivates change.

Some readers will identify in this a description of continuous quality improvement and others might recognise it as total quality management. Much has been written about the development of total quality management in industry and its relevance to health care. In health care, quality is almost exclusively focused on clinical quality; there is a tendency to disassociate managerial and clinical activity within quality improvement. In total quality management the idea of quality improvement is linked to the notion that quality is a characteristic of the whole organisation. This approach to quality improvement was developed by American experts asked by Japanese industrialists to advise about improving Japanese industrial production processes. These advisors, among them W Edwards Deming and Joseph $M$ Duran, understood that documenting the technical quality or specifications of components on a production line would not alone produce lasting improvement in production quality. They approached quality improvement from a much wider perspective. Drawing from a wide range of disciplines, they advocated the development of an approach to quality improvement that involves everyone in the organisation as part of a continual drive to do better. The box shows some of the characteristics of total quality management. Although total quality management may sound like jargon to people working in health care and its industrial origins may provoke resistance, it is an approach which could be applied to the National Health Service. ${ }^{24} 25$

Some of the characteristics of total quality management are similar to those of risk management - for example, examining the processes of care rather than individual performance for explanations of flaws or errors. Others, in particular the emphasis on measurement, are in line with the principles that underpin audit. The need to develop an integrated approach to quality and its improvement and to avoid separating those

\section{Some characteristics of total quality} management ${ }^{\star}$

Making customers' needs a priority for everyone Defining quality in terms of customer needs

Recognising the existence of internal customers and suppliers

Examining the process of production rather than individual performance for explanations of flaws or poor quality

Using sound measurement to understand how to improve quality

Removing barriers between staff and promoting effective teamwork

Promoting training for everyone

Involving the whole workforce in the task of improving quality

Understanding that quality improvement is a continuous process

${ }^{\star}$ From Moss and Garside ${ }^{23}$

programmes that within one organisation aim at improving the quality of care would be in keeping with total quality management.

COMPARING THE CONTRIBUTIONS OF RISK MANAGEMENT AND CLINICAL AUDIT

Risk management and clinical audit focus on different aspects of the quality of care and are complementary, not alternative, programmes. Structure is more often a topic for risk management than clinical audit. Safety depends on good, well maintained equipment, and hospitals should have a mechanism to detect faulty equipment. Staffing also affects the quality of care. The national confidential enquiry in perioperative deaths highlighted the risks of operations being done by surgeons of inappropriate seniority for the tasks they are asked to do. Buildings also need to be safe, well maintained, and to provide the appropriate environment for patients and for staff.

Much audit activity is about the process of care, which is relatively easy to measure. The importance of the process of care is its relation to outcome and the presupposition of a relation between the appropriate use of an effective intervention and a favourable outcome. Both (in)effective and (in)appropriate care interventions may be a focus for audit. By setting standards and measuring care against them the degree to which care meets those standards can be assessed. An example is the use of thrombolytic therapy for people with myocardial infarction - an intervention of proven benefit. Reasonable targets for audit, as process markers of good quality care, are the rate and timing of administration of thrombolytic therapy. Many hospitals, through the audit process, know the proportion of patients admitted with myocardial infarction who receive thrombolytic therapy and the delay between arrival in hospital and receiving this treatment. This information, used properly, can help a hospital to improve this aspect of care. $^{26}$

In contrast, effectiveness and appropriateness are not prime targets for risk management programmes, although questions about these aspects of quality may be asked when an untoward event has occurred. Sometimes the 
process of care is a trigger for risk management, but the targets are unexpected activity and indicators of problems with care. For example, a need for a patient to return to theatre after an operation or a greater than predicted blood transfusion after a caesarean delivery is an intervention that might indicate that something had not gone according to plan.

The government white paper Working for Patients included outcomes within the working definition of medical audit. ${ }^{27}$ In reality using outcome for audit is difficult. Problems of case mix, different perspectives on outcome, the need for large numbers to make sense of small changes, and the importance of medium and long term outcomes which may be difficult to collect at discharge have thwarted attempts to audit outcome. For to act as a lever for change a link with process is needed. Some outcomes are most usefully measured some time after the intervention so that both collecting the data and communicating them to the healthcare professionals who initiated the intervention may not be straightforward.

Unwanted outcomes or adverse outcomes are important triggers in risk management. Unexpected death or a complication from an intervention warrants investigation. Each specialty will have its own series of such outcomes - for example, a poor apgar score of a newborn baby, neonatal death, or any death after an elective operation.

Most instances of care that patients find unacceptable are probably unreported and are unlikely to be disclosed by any of the quality improvement initiatives. Acceptability of care is not a usual focus for audit but may be detected through risk management programmes, in some cases passing through the clinical complaints process. One study of clinical complaints found that most complaints were seldom about a clinical problem alone; most also included some dissatisfaction with personal treatment. ${ }^{28}$

\section{CONTINUOUS QUALITY IMPROVEMENT}

Firm links between clinical and managerial activity are necessary if risk management or clinical audit is to be effective. All these initiatives depend on organisational support and the cooperation and the involvement of all staff. An organisation that works through the principles of continuous quality improvement will be responsive to the demands of both audit and risk management and enable links between these and other similar programmes. A workforce receptive to the notion of continuous quality improvement is likely to adopt a positive attitude to the reporting systems that are part of risk management. And some features of good quality care - allowing patient choice, assuring equity, and providing information - are difficult to measure and rarely assessed. But these aspects of quality will be integral to organisations whose functions are based on the principles of continuous quality improvement because of the emphasis on the needs of their customers and the importance given to training of all staff. The success of risk management may depend on the adoption of the principles of continuous quality improvement.

\section{Conclusions}

Good quality care is more than either average care or simply care free of mistakes. No single technology that purports to improve the quality of care can encompass the many dimensions of quality. Some aspects of quality are more easily targeted by audit and others by risk management; and some are unlikely to be the focus of either programme. In the United Kingdom the development of clinical risk management is being introduced after the implementation of clinical audit. With their separate funding and perhaps their aim at primarily different groups within the health service, there is a risk that clinical audit and risk management will develop separately. They should be linked by good organisational support.

1 Maxwell, R. Quality assessment in health. BMF 1984; 288:1470-2.

2 Donabedian A. Evaluating the quality of medical care. Millbank Memorial Fund Quarterly 1966;44:166-206.

3 Donabedian A. The definition of quality and approaches to its assessment. Ann Arbor, Michigan: Health Administration Press, 1980

4 Maxwell R. Dimensions of quality revisited: from thought to action. Quality in Health Care 1992;1:171-7.

5 Shanks J, Frater A. Health status, outcome, and attributality: is a red rose red in the dark? Quality in Health Care 1993;2:259-62.

6 Brazier JE, Harper R, Jones NMB, O'Cathain A, Thomas KJ, Usherwood T, et al. Validating the SF-36 health survey questionnaire: new outcome measure for health survey questionnaire: new outc

7 Hopkins A. Measuring the quality of medical care. London: Royal College of Physicians of London, 1990.

8 Eccles M, Bradshaw C. Use of secondary prophylaxis against myocardial infarction in the north of England. BMF 1991;302:91-2.

9 What do we mean by appropriate health care? Report of a working group prepared for the Director of Research and Development of the NHS Management Executive. Quality in Health Care 1993;2:117-23.

10 Gray D, Hampton JR, Bernstein SJ, Kosekoff J, Brook R. Audit of coronary angiography and bypass surgery. Lancet 1990;335:1317-20.

11 Mullin J. Leukaemia girl loses court fight. Guardian 11 March 1995:1.

12 Mihill C. Guideline plea for rationing treatment. Guardian 11 March 1995.

13 Collins C. Implementing the patient's charter in outpatient services. BMF 1993;302:1396

14 Black N. Jennifer's ear: airing the issues. Quality in Health Care 1992;1:213-4.

15 Wareham NJ. External monitoring of quality of health care in the United States. Quality in Health Care 1994; 3:97-101.

16 Wareham NJ. Changing systems of external monitoring of quality of health care in the United States. Quality in quality of health care in the

17 Buck N, Devlin HB, Lunn JN. Report of a confidential enquiry into perioperative deaths. London: Nuffield Provincial Hospitals Trusts, 1988

18 Department of Health. Medical audit in the family practitioner services. London: HMSO, 1990. (HC(FP) 90(8).

19 Department of Health. Medical audit in the hospital and community services. London: HMSO, 1991. (HC 91(2).)

20 Russell IT, Wilson BJ. Audit: the third clinical science? Quality in Health Care 1992;1:51-5.

21 Crombie IK, Davies HTO. Missing link in the audit cycle. Quality in Health Care 1993;2:47-8.

22 Buxton $M$. Achievements of audit in the NHS. Quality in Health Care 1994;3(suppl):S31-4.

23 Moss F, Garside P. The importance of quality: sharing responsibilities for improving patient care. BMY responsibilities for

24 Berwick DM, Enthoven A, Bunker JP. Quality management in the NHS: the doctor's role. I. BMf 1992;394:235-9.

25 Berwick DM, Enthoven A, Bunker JP. Quality managemen in the NHS: the doctor's role. II. BMf 1992;304:304-8.

26 Nee PA, Gray AJ, Martin MA. Audit of thrombolysis initiated in an accident and emergency department. Quality in Health Care 1994;2:29-33.

27 Secretaries of State for Health, Wales, Northern Ireland, and Scotland. Medical audit. Working paper 6. London: HMSO, 1989.

28 Bark P, Vincent C, Jones A, Savory J. Clinical complaints: a means of improving quality of care. Quality in Health Care 1994;3:123-32. 